\title{
Methylenetetrahydrofolate reductase gene polymorphism as a risk factor for diabetic nephropathy: a meta-analysis
}

\author{
Elias Zintzaras · Katrin Uhlig · George N. Koukoulis • \\ Afroditi A. Papathanasiou - Ioannis Stefanidis
}

Received: 15 June 2007 / Accepted: 4 August 2007/Published online: 6 September 2007

(C) The Japan Society of Human Genetics and Springer 2007

\begin{abstract}
Investigations into the association between diabetic nephropathy (DN) and MTHFR C677T gene polymorphism in several case-control studies has yielded contradictory results. To shed light on these inconclusive findings, a meta-analysis of all available studies relating the C677T polymorphism to the risk of developing DN was conducted. The PubMed database was searched, and casecontrol studies investigating the association between MTHFR C677T gene polymorphism and DN were included in the meta-analysis. The meta-analysis included 15 studies, of which 8 involved Caucasians and 5 East Asians; 11 studies involved subjects with type 2 diabetes and 4
\end{abstract}

E. Zintzaras $(\bowtie) \cdot$ A. A. Papathanasiou

Department of Biomathematics,

University of Thessaly School of Medicine,

Papakyriazi 22, Larissa 41222, Greece

e-mail: zintza@med.uth.gr

\section{E. Zintzaras}

Center for Clinical Evidence Synthesis,

Institute for Clinical Research and Health Policy Studies,

Tufts-New England Medical Center,

Tufts University School of Medicine,

Boston, MA, USA

\section{K. Uhlig}

Division of Nephrology, Tufts-New England Medical Center,

Boston, MA, USA

G. N. Koukoulis

Department of Endocrinology,

University of Thessaly School of Medicine,

Larissa, Greece

I. Stefanidis

Department of Nephrology,

University of Thessaly School of Medicine,

Larissa, Greece with type 1 diabetes. The main analysis (all studies) revealed significant heterogeneity between the studies $\left(P_{\mathrm{Q}}<0.01\right)$ and a marginal association between the 677T allele and the risk of developing DN; the random effects (RE) pooled odds ratio (OR) was 1.30 (1.03-1.64). However, the sensitivity analysis (exclusion of studies not in Hardy-Weinberg equilibrium) produced non-significant results. The recessive model derived significant results in main analysis [fixed effects (FE) $\mathrm{OR}=1.32(1.10-1.58)$, $P_{\mathrm{Q}}=0.27$ ], and in type 2 diabetes [FE OR $=1.30(1.06-$ 1.60), $\left.P_{\mathrm{Q}}=0.38\right]$. The additive model produced significant association in main analysis [RE OR $=1.65(1.13-2.42)$, $\left.P_{\mathrm{Q}}<0.01\right]$ in Caucasians [FE OR $=1.48(1.11-1.98)$, $\left.P_{\mathrm{Q}}=0.17\right]$ and in type 2 diabetes $[\mathrm{RE} \mathrm{OR}=1.65(1.03-$ 2.67), $\left.P_{\mathrm{Q}}<0.01\right]$. However, sensitivity analysis diminished the significant results in type 2 diabetes. There is no differential magnitude of effect in large versus small studies. In conclusion, although there is some evidence of association between MTHFR C677T gene polymorphism and DN, the above findings reinforce the need for further and more rigorous association studies.

Keywords Diabetic nephropathy - MTHFR - C677T · Polymorphism - Meta-analysis · Genetic epidemiology · Type 1 diabetes . Type 2 diabetes

\section{Introduction}

Diabetic nephropathy (DN) is a serious chronic microangiopathic complication of both type 1 and type 2 diabetes, and is the primary cause of end-stage renal failure (Gross et al. 2005). The etiology of DN is multifactorial and involves both environmental and genetic factors (Shpichinetsky et al. 2000; Zintzaras and Stefanidis 2005). 
A familial clustering of $\mathrm{DN}$ indicated that a genetic predisposition is implicated in the pathogenesis of DN in both types of diabetes (Borch-Johnsen et al. 1992; Quinn et al. 1996; Strojek et al. 1997). Methylenetetrahydrofolate reductase (MTHFR) catalyses the conversion of 5,10methylenetetrahydrofolate to 5-methyltetrahydrofolate, a co-substrate for transmethylation of homocysteine to methionine. An elevated plasma homocysteine level has been identified as an independent risk factor for macroangiopathy (cerebrovascular or coronary artery disease), and for arterial or venous thrombosis (Bostom et al. 2001; Boushey et al. 1995; McCully 1996). A C677T transition is a common ubiquitous missense mutation in the coding region of the MTHFR gene (chromosome 1p36.3) (Goyette et al. 1994), causing an alanine to valine (Al222Val) amino acid substitution located in the anticipated catalytic domain of the enzyme (Frosst et al. 1995) and resulting in a thermo-labile MTHFR variant with reduced catalytic activity. Homozygosity for the mutation (TT genotype) predisposes to significantly elevated plasma homocysteine levels (Frosst et al. 1995; Kang et al. 1991). Thus, MTHFR C677T gene polymorphism associated with a predisposition to increased plasma homocysteine levels may present a genetic risk factor for DN (Sun et al. 2004), a form of diabetic microangiopathy.

Case-control studies investigating the association between C677T gene polymorphism and DN have so far provided conflicting or inconclusive results. Each study involved only a small number of cases and controls, and data interpretation was complicated by the fact that different populations and sampling strategies were used. In order to shed some light on these controversial results, as well as to decrease the uncertainty of the effect size of estimated risk, a meta-analysis of all available studies relating the C677T polymorphism of the MTHFR gene to the risk of developing DN was carried out. In this metaanalysis, a pooled estimate of the risk was obtained for the allele contrast, and the additive and dominance models. In addition, the heterogeneity between studies and the existence of bias were investigated.

\section{Materials and methods}

Selection of studies

All studies published before January 2007 were identified by extended computer-based searches of the PubMed database. The following search criterion was used: ("MTHFR" or "Methylenetetrahydrofolate reductase" or "C677T") and "diabetic nephropathy". The retrieved studies were then read in their entirety to assess their appropriateness for inclusion in the meta-analysis. All references cited in the studies were also reviewed to identify additional published work not indexed by the PubMed database. Case reports, editorials and review articles were excluded. The search was restricted to articles in English.

Case-control studies that determine the genotype distribution of the C677T polymorphism in cases with diabetes and nephropathy, and in controls with diabetes and free of diabetic nephropathy were eligible for inclusion in the meta-analysis. Cases with diabetes were considered as diabetic nephropathy on the basis of a persistent albuminuria (i.e. macroalbuminuria, equivalent to an overt glomerular proteinuria) or a persistent microalbuminuria with or without chronic renal insufficiency and in the absence of non-diabetic renal disease. Case groups that consisted exclusively of subjects with microalbuminuria were excluded from the meta-analysis. The control groups consisted of subjects with diabetes and free of diabetic kidney disease, i.e. normoalbuminuria (urinary albumin excretion $<20 \mathrm{mg} / 24 \mathrm{~h}$ or $<20 \mu \mathrm{g} / \mathrm{min}$ ) and normal renal function. The different methods used in the studies to determine urinary albumin excretion and the respective cut-offs to define macro- or microalbuminuria were all equivalent and previously clinically validated (Gross et al. 2005) (Table 1). Only studies in human subjects and having used validated genotyping methods were considered (Frosst et al. 1995). Genome scans were excluded since they investigate linkage (Zintzaras and Ioannidis 2005a), and family-based studies association studies were also not considered because of different design considerations.

\section{Data extraction}

From each study the following information was extracted: first author, journal, year of publication, ethnicity of the study population, demographics, clinical characteristics, matching, validity of the genotyping method, and the number of cases and controls. The frequencies of the alleles and the genotypic distributions were extracted or calculated for both cases and controls. In addition, whether the genotyping in each study was blinded to clinical status was recorded.

Meta-analysis

The meta-analysis examined the overall association of the $\mathrm{T}$ allele with the risk of $\mathrm{DN}$ relative to the $\mathrm{C}$ allele, the recessive model for $\mathrm{T}$ allele (TT vs $\mathrm{TC}+\mathrm{CC}$ ), the dominant model for $\mathrm{T}$ allele (TC $+\mathrm{TT}$ vs $\mathrm{CC}$ ), the additive model for allele $\mathrm{T}$ (TT vs $\mathrm{CC}$ ), and the co-dominance model (TC vs TT + CC). All associations were indicated as odds ratios (OR) with the corresponding 95\% confidence 


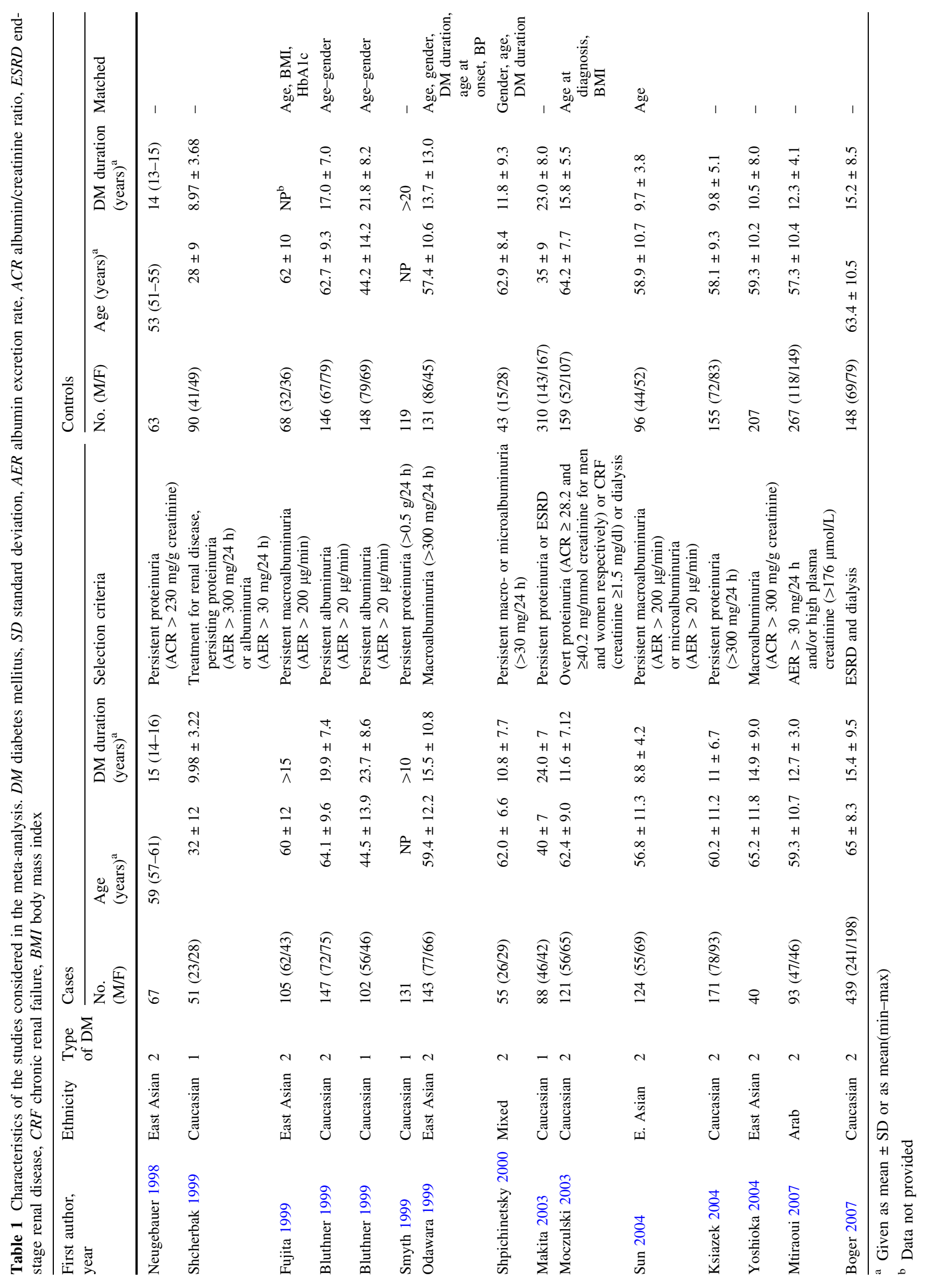


interval (CI). A pooled OR was then estimated based on the individual ORs.

The heterogeneity between studies was tested using the Q-statistic, which is a weighted sum of squares of the deviations of individual study OR estimates from the overall estimate (Ioannidis et al. 2006; Zintzaras and Ioannidis 2005b). Heterogeneity was considered statistically significant if $P_{\mathrm{Q}}<0.10$. Heterogeneity was quantified with the $I^{2}$ metric, which is independent of the number of studies in the meta-analysis (Zintzaras and Hadjigeorgiou 2004). $I^{2}$ takes values between 0 and $100 \%$, with higher values denoting a greater degree of heterogeneity $\left(I^{2}=0-25 \%\right.$ : no heterogeneity; $I^{2}=25-50 \%$ : moderate heterogeneity; $I^{2}=50-75 \%$ : large heterogeneity; $I^{2}=75-100 \%$ : extreme heterogeneity; when $I^{2}<0$ then $I^{2}=0$ ).

The pooled OR was estimated using fixed effects (Mantel-Haenszel) and random effects (DerSimonian and Laird) models (DerSimonian and Laird 1986). The calculation of pooled OR and Q used as a weighting factor $\left(w_{\mathrm{i}}\right)$, the inverse variance of $\theta_{\mathrm{i}}=\operatorname{lnOR}\left[\right.$ i.e. $w_{\mathrm{i}}=1 / \operatorname{var}\left(\theta_{\mathrm{i}}\right)$ ] of each study $i$. Random effects modelling assumes a genuine diversity in the results of various studies and incorporates a between-study variance into the calculations. Therefore, when there is heterogeneity between studies, the pooled OR is estimated using the RE model (Whitehead 2002).

A cumulative and recursive cumulative meta-analysis was carried out for each polymorphism to evaluate the trend of RE OR in time for the genetic contrast under investigation (Lau et al. 1992; Zintzaras et al. 2006a). In cumulative meta-analysis, studies were chronologically ordered by publication year; the pooled ORs were then obtained at the end of each year, i.e. at each information step. In recursive cumulative meta-analysis, the relative change in pooled OR in each information step (OR in next year/OR in current year) was calculated (Zintzaras et al. 2006b). Thus, cumulative and recursive cumulative metaanalysis provide a framework for updating a genetic effect from all studies and a measure of how much the genetic effect changes as evidence accumulates (Zintzaras 2007).

A differential magnitude of effect in large versus small studies (Zintzaras 2006a; Zintzaras and Hadjigeorgiou 2005) for the genetic contrast under investigation was checked using the Egger regression test for funnel plot asymmetry (Egger et al. 1997a, b) and the Begg-Mazumdar test, which is based on Kendall's tau (Begg and Mazumdar 1994). Given that these tests are underpowered, they were always considered statistically significant for $P<0.10$ rather than for $P<0.05$. Whether the OR of the allele contrast in the first study versus the pooled OR of subsequent studies were different beyond chance $(P<0.05)$ was assessed using the $Z$-statistic (Zintzaras et al. 2005).

In addition to the main (or overall) analysis, which included all available data, subgroup analysis for each ethnic group and diabetes type was also performed. The distribution of the genotypes in the control group was tested for Hardy-Weinberg equilibrium (HWE) using an exact test $(P \geq 0.05)$ (Weir 1996). Studies with controls not in HWE were subjected to a sensitivity analysis (Zintzaras 2006c). Lack of HWE indicates possible genotyping errors and/or population stratification (Zintzaras and Hadjigeorgiou 2004). In sensitivity analysis, the effect of excluding specific studies was examined. Analyses were performed using Meta-Analyst (Joseph Lau, Boston, MA, USA 1998) and CVF90 with IMSL library (Zintzaras et al. 2006d; Zintzaras 2006b).

\section{Results}

\section{Eligible studies}

The literature review identified 29 titles in PubMed that met the search criterion. The full articles of the retrieved studies were read to assess their appropriateness for metaanalysis according to the inclusion criteria. Data from 14 articles that investigated the association C677T and DN met the inclusion criteria and were included in the metaanalysis. One article (Bluthner et al. 1999) provided data on both type 1 and type 2 diabetes separately. Thus, data were obtained from 15 studies. Data were extracted by two investigators (G.K. and K.U.) and disagreements were resolved by discussion. The studies were published between 1998 and 2007.

In all studies, validated genotyping methods were used for the determination of the genetic polymorphism; namely, polymerase chain reaction (PCR) analysis followed by HinfI digestion (Frosst et al. 1995), except one study that used PCR with allele-specific probes (Makita et al. 2003). Seven studies stated that the controls were age-, sex-, HbA1c-, body mass index (BMI)- or diabetes duration-matched (Shpichinetsky et al. 2000; Sun et al. 2004; Bluthner et al. 1999; Fujita et al. 1999; Odawara and Yamashita 1999; Moczulski et al. 2003). Studies were conducted in populations of various ethnicity: eight involved Caucasians (Bluthner et al. 1999; Makita et al. 2003; Moczulski et al. 2003; Boger et al. 2007; Ksiazek et al. 2004; Shcherbak et al. 1999; Smyth et al. 1999), five East Asians (Sun et al. 2004; Fujita et al. 1999; Odawara and Yamashita 1999; Neugebauer et al. 1998; Yoshioka et al. 2004), one a mixed population (Shpichinetsky et al. 2000), and one Arabs (Mtiraoui et al. 2007). Eleven studies involved cases with type 2 diabetes (Shpichinetsky et al. 2000; Sun et al. 2004; Bluthner et al. 1999; Fujita et al. 1999; Odawara and Yamashita 1999; Moczulski et al. 2003; Boger et al. 2007; Ksiazek et al. 2004; Neugebauer et al. 1998; Mtiraoui et al. 2007; Yoshioka et al. 2004), and 
Table 2 The distribution of the MTHFR C677T genotypes for cases and controls and the allele frequencies (in parenthesis are the respective percentages). The significance level ( $P$-value) for Hardy-Weinberg equilibrium (HWE) testing for controls is shown

\begin{tabular}{|c|c|c|c|c|c|c|c|c|c|c|c|}
\hline \multirow[t]{2}{*}{ First author, year } & \multicolumn{2}{|l|}{$\mathrm{TT}$} & \multicolumn{2}{|l|}{$\mathrm{TC}$} & \multicolumn{2}{|l|}{$\mathrm{CC}$} & \multicolumn{2}{|l|}{$\mathrm{T}$} & \multicolumn{2}{|l|}{ C } & \multirow{2}{*}{$\begin{array}{l}P \text {-value } \\
\text { HWE }\end{array}$} \\
\hline & Cases & Controls & Cases & Controls & Cases & Controls & Cases & Controls & Cases & Controls & \\
\hline Neugebauer 1998 & 12 (17) & $8(12)$ & $31(46)$ & $18(28)$ & $24(35)$ & $37(58)$ & $55(41)$ & $34(26)$ & $79(58)$ & $92(73)$ & 0.03 \\
\hline Shcherback 1999 & $11(21)$ & $5(5)$ & $21(41)$ & $29(32)$ & $19(37)$ & $56(62)$ & $43(42)$ & $39(21)$ & $59(57)$ & $141(78)$ & 0.63 \\
\hline Fujita 1999 & $17(16)$ & $9(13)$ & $57(54)$ & $39(57)$ & $31(29)$ & $20(29)$ & $91(43)$ & $57(41)$ & $119(56)$ & $79(58)$ & 0.14 \\
\hline $\begin{array}{l}\text { Bluthner } \\
\quad \text { (type 2) } 1999\end{array}$ & $23(15)$ & $18(12)$ & $50(34)$ & $65(44)$ & $74(50)$ & $63(43)$ & $96(32)$ & $101(34)$ & $198(67)$ & $191(65)$ & 0.85 \\
\hline $\begin{array}{l}\text { Bluthner } \\
\quad \text { (type 1), } 1999\end{array}$ & $13(12)$ & $18(12)$ & $54(52)$ & $67(45)$ & $35(34)$ & $63(42)$ & $80(39)$ & $103(34)$ & $124(60)$ & $193(65)$ & 0.98 \\
\hline Smyth 1999 & $16(12)$ & $15(12)$ & $62(47)$ & $57(47)$ & $53(40)$ & 47 (39) & $94(35)$ & $87(36)$ & $168(64)$ & $151(63)$ & 0.72 \\
\hline Odawara 1999 & $26(18)$ & 25 (19) & $65(45)$ & $68(51)$ & $52(36)$ & $38(29)$ & $117(40)$ & $118(45)$ & $169(59)$ & $144(54)$ & 0.57 \\
\hline Shpichinetsky 2000 & $10(18)$ & $6(13)$ & $22(40)$ & $16(37)$ & $23(41)$ & $21(48)$ & $42(38)$ & $28(32)$ & $68(61)$ & $58(67)$ & 0.32 \\
\hline Makita 2003 & 13 (14) & $32(10)$ & 35 (39) & $143(46)$ & $40(45)$ & $135(43)$ & $61(34)$ & 207 (33) & $115(65)$ & $413(66)$ & 0.51 \\
\hline Moczulski 2003 & $76(62)^{\mathrm{a}}$ & $84(52)^{\mathrm{a}}$ & & & $45(37)$ & $75(47)$ & & & & & $\mathrm{NA}^{\mathrm{b}}$ \\
\hline Sun 2004 & $26(20)$ & $16(16)$ & $53(42)$ & $23(23)$ & $45(36)$ & $57(59)$ & $105(42)$ & $55(28)$ & $143(57)$ & $137(71)$ & 0.00 \\
\hline Ksiazek 2004 & $29(16)$ & $15(9)$, & $65(38)$ & $58(37)$ & 77 (45) & $82(52)$ & $123(35)$ & $88(28)$ & $219(64)$ & $222(71)$ & 0.32 \\
\hline Yoshioka 2004 & $6(15)$ & $29(14)$ & $13(32)$ & $107(51)$ & $21(52)$ & $71(34)$ & $25(31)$ & 165 (39) & $55(68)$ & $249(60)$ & 0.26 \\
\hline Mtiraoui 2007 & $26(27)$ & $36(13)$ & $56(60)$ & 79 (29) & $11(11)$ & $152(56)$ & $108(58)$ & $151(28)$ & $78(41)$ & $383(71)$ & 0.00 \\
\hline Boger 2007 & $188(42)$ & $64(43)$ & 219 (49) & $69(46)$ & $32(7)$ & $15(10)$ & $595(67)$ & 197 (66) & $283(32)$ & 99 (33) & 0.56 \\
\hline Total & $492(26)$ & $380(17)$ & $803(42)$ & $838(38)$ & $582(31)$ & $932(43)$ & $1,635(46)$ & $1,430(35)$ & $1,877(53)$ & $2,552(64)$ & \\
\hline
\end{tabular}

${ }^{a}$ Data concerned $(\mathrm{TC}+\mathrm{TT})$

b Non-applicable

four type 1 diabetes (Bluthner et al. 1999; Makita et al. 2003; Shcherbak et al. 1999; Smyth et al. 1999). One study provided data for males and females separately (Moczulski et al. 2003). Three studies (Smyth et al. 1999; Neugebauer et al. 1998; Yoshioka et al. 2004) did not specify gender. One study (Bluthner et al. 1999) did not specify what proportion of cases had microalbuminuria.

Sensitivity analyses were performed for studies that may involve cases with microalbuminuria (Shcherbak et al. 1999; Bluthner et al. 1999; Shpichinetsky et al. 2000; Sun et al. 2004; Mtiraoui et al. 2007), and for studies involving cases with chronic renal failure (CRF) and/or end stage renal disease (ESRD) (Makita et al. 2003; Moczulski et al. 2003; Mtiraoui et al. 2007; Boger et al. 2007). A list of details abstracted from the studies included in the metaanalysis is provided in Table 1 .

\section{Summary statistics}

The studies provided 1,877 cases and 2,150 controls. The allele $C$ was the most common. The frequencies of the CC and TC genotypes were the highest in controls and in cases, respectively, while that for genotype TT was the lowest (Table 2). One study (Moczulski et al. 2003) did not provide data for all genotypes separately; it provided data only for T-carriers. In three studies (Sun et al. 2004; Neugebauer et al. 1998; Mtiraoui et al. 2007), the distribution of the genotypes in the control group was not in HWE $(P<0.05)$ (Table 2).

Main results, subgroup and sensitivity analyses

Table 3 and Fig. 1 show the results for the association between the C677T gene polymorphism and the risk of DN.

The main analysis for investigating the association between C677T allele $\mathrm{T}$ and the risk of developing DN relative to the allele $\mathrm{C}$ revealed significant heterogeneity $\left(P_{\mathrm{Q}}<0.01, I^{2}=80 \%\right)$ between the 14 studies; the random effects pooled OR was marginally significant: $\mathrm{RE} O \mathrm{OR}=1.30$ (1.03-1.64). However, the sensitivity analysis for HWE (exclusion of studies not in HWE) yielded non-significant results. The sensitivity analyses for microalbuminuria (exclusion of studies involving cases with microalbuminuria), and for CRF/ESRD (exclusion of studies involving cases with CRF/ESRD) also yielded non-significant results. In subgroup analysis, there was significant heterogeneity in Caucasians and East Asians $\left(P_{\mathrm{Q}}=0.03, I^{2}=57 \%\right.$ and $P_{\mathrm{Q}}<0.01, I^{2}=75 \%$, respectively), and the associations were not significant: $\mathrm{RE} O \mathrm{OR}=1.19(0.97-1.46)$ and $\mathrm{RE}$ $\mathrm{OR}=1.16(0.79-1.17)$, respectively. In type 1 and 2 
Table 3 Summary estimates for the odds ratio (OR) of MTHFR C677T in various allele/genotype contrasts, the significance level ( $P$-value) of heterogeneity test $(Q$-test) and the $I^{2}$ metric (when negative was set to zero): overall analysis, subgroup analyses and sensitivity analysis

\footnotetext{
${ }^{a}$ Exclusion of studies with the controls not in HWE

b Exclusion of studies that may involve cases with microalbuminuria

${ }^{c}$ Exclusion of studies that involve cases with CRF and/or ESRD
}

\begin{tabular}{|c|c|c|c|c|c|c|}
\hline $\begin{array}{l}\text { Genetic } \\
\text { contrasts }\end{array}$ & Studied population & $\begin{array}{l}\text { Studies } \\
(N)\end{array}$ & $\begin{array}{l}\text { Fixed effects } \\
\text { OR }(95 \% \text { CI) }\end{array}$ & $\begin{array}{l}\text { Random } \\
\text { effects } \\
\text { OR }(95 \% \text { CI) }\end{array}$ & $\begin{array}{l}I^{2} \\
(\%)\end{array}$ & $\begin{array}{l}P \text {-value } \\
Q \text {-test }\end{array}$ \\
\hline \multirow[t]{10}{*}{$\mathrm{T}$ vs $\mathrm{C}$} & All & 14 & $1.27(1.15-1.40)$ & $1.30(1.03-1.64)$ & 80 & $<0.01$ \\
\hline & Excluded $\mathrm{HWE}^{\mathrm{a}}$ & 11 & $1.08(0.97-1.21)$ & $1.10(0.93-1.30)$ & 51 & 0.03 \\
\hline & $\begin{array}{l}\text { Excluded } \\
\text { microalbumuria }^{\mathrm{b}}\end{array}$ & 8 & $1.07(0.94-1.22)$ & $1.07(0.90-1.28)$ & 43 & 0.09 \\
\hline & Excluded CRF/ESRD ${ }^{c}$ & 11 & $1.18(1.5-1.34)$ & $1.22(0.99-1.51)$ & 66 & $<0.01$ \\
\hline & Caucasian & 7 & $1.16(1.01-1.32)$ & $1.19(0.97-1.46)$ & 57 & 0.03 \\
\hline & East Asian & 5 & $1.13(0.94-1.37)$ & $\begin{array}{c}1.16(0.79- \\
1.170)\end{array}$ & 75 & $<0.01$ \\
\hline & East Asian in HWE & 3 & $0.86(0.68-1.09)$ & $0.86(0.68-1.10)$ & 0 & 0.04 \\
\hline & Type1 diabetes & 4 & $1.21(1.00-1.47)$ & $1.29(0.90-1.86)$ & 71 & 0.02 \\
\hline & Type 2 diabetes & 10 & $1.29(1.15-1.45)$ & $1.30(0.95-1.76)$ & 84 & $<0.01$ \\
\hline & Type 2 diabetes in HWE & 7 & $1.02(0.89-1.18)$ & $1.02(0.86-1.21)$ & 28 & 0.22 \\
\hline \multirow{10}{*}{$\begin{array}{l}\text { Recessive model } \\
\text { for allele T }\end{array}$} & All & 14 & $1.32(1.10-1.58)$ & $1.35(1.10-1.66)$ & 17 & 0.27 \\
\hline & Excluded $\mathrm{HWE}^{\mathrm{a}}$ & 11 & $1.21(0.99-1.50)$ & $1.22(0.99-1.50)$ & 2 & 0.42 \\
\hline & $\begin{array}{l}\text { Excluded } \\
\text { microalbumuria }^{\mathrm{b}}\end{array}$ & 8 & $1.16(0.92-1.45)$ & $0.16(0.92-1.45)$ & 0 & 0.73 \\
\hline & Excluded CRF/ESRD ${ }^{c}$ & 11 & $1.32(1.05-1.67)$ & $1.31(1.04-1.66)$ & 0 & 0.58 \\
\hline & Caucasian & 7 & $1.26(1.00-1.59)$ & $1.34(0.98-1.83)$ & 36 & 0.06 \\
\hline & East Asian & 5 & $1.17(0.83-1.65)$ & $1.17(0.82-1.65)$ & 0 & 0.92 \\
\hline & East Asian in HWE & 3 & $1.05(0.67-1.63)$ & $1.05(0.67-1.63)$ & 0 & 0.86 \\
\hline & Type1 diabetes & 4 & $1.40(0.95-2.07)$ & $1.48(0.83-2.61)$ & 50 & 0.11 \\
\hline & Type 2 diabetes & 10 & $1.30(1.06-1.60)$ & $1.31(1.06-1.63)$ & 7 & 0.38 \\
\hline & Type2 diabetes in HWE & 7 & $1.16(0.91-1.47)$ & $1.15(0.91-1.46)$ & 0 & 0.73 \\
\hline \multirow{10}{*}{$\begin{array}{l}\text { Dominant model } \\
\text { for allele } \mathrm{T}\end{array}$} & All & 15 & $1.38(1.20-1.59)$ & $1.41(1.01-1.97)$ & 81 & $<0.01$ \\
\hline & Excluded $\mathrm{HWE}^{\mathrm{a}}$ & 12 & $1.09(0.93-1.27)$ & $1.09(0.87-1.38)$ & 52 & 0.02 \\
\hline & $\begin{array}{l}\text { Excluded } \\
\text { microalbumuria }{ }^{\mathrm{b}}\end{array}$ & 9 & $1.10(0.92-1.31)$ & $1.09(0.83-1.44)$ & 56 & 0.02 \\
\hline & Excluded CRF/ESRD ${ }^{c}$ & 11 & $1.19(1.01-1.41)$ & $1.23(0.89-1.69)$ & 71 & $<0.01$ \\
\hline & Caucasian & 8 & $1.27(1.01-1.44)$ & $1.24(0.96-1.59)$ & 47 & 0.06 \\
\hline & East Asian & 5 & $1.17(0.90-1.53)$ & $1.17(0.61-2.27)$ & 83 & $<0.01$ \\
\hline & East Asian in HWE & 3 & $0.70(0.50-1.00)$ & $0.70(0.48-1.03)$ & 14 & 0.31 \\
\hline & Type1 diabetes & 4 & $1.23(0.94-1.60)$ & $1.30(0.84-2.00)$ & 61 & 0.06 \\
\hline & Type2 diabetes & 11 & $1.45(1.23-1.70)$ & $1.45(0.93-2.25)$ & 85 & $<0.01$ \\
\hline & Type 2 diabetes in HWE & 8 & $1.02(0.84-1.23)$ & $1.01(0.76-1.34)$ & 51 & 0.05 \\
\hline \multirow[t]{10}{*}{ Additive model } & All & 14 & $1.61(1.30-2.00)$ & $1.65(1.13-2.42)$ & 66 & $<0.01$ \\
\hline & Excluded $\mathrm{HWE}^{\mathrm{a}}$ & 11 & $1.29(1.01-1.64)$ & $1.30(0.97-1.73)$ & 26 & 0.19 \\
\hline & $\begin{array}{l}\text { Excluded } \\
\text { microalbumuria }^{\mathrm{b}}\end{array}$ & 8 & $1.24(0.94-1.64)$ & $1.24(0.93-1.65)$ & 3 & 0.41 \\
\hline & Excluded CRF/ESRD ${ }^{c}$ & 11 & $1.39(1.08-1.78)$ & $1.41(1.02-1.96)$ & 38 & 0.10 \\
\hline & Caucasian & 7 & $1.48(1.11-1.98)$ & $1.50(1.05-2.15)$ & 33 & 0.17 \\
\hline & East Asian & 5 & $1.22(0.84-1.77)$ & $1.24(0.76-2.02)$ & 38 & 0.17 \\
\hline & East Asian in HWE & 3 & $0.84(0.51-1.37)$ & $0.84(0.51-1.37)$ & 0 & 0.69 \\
\hline & Type1 diabetes & 4 & $1.51(1.00-2.28)$ & $1.64(0.83-3.22)$ & 59 & 0.28 \\
\hline & Type2 diabetes & 10 & $1.65(1.29-2.11)$ & $1.65(1.03-2.67)$ & 71 & $<0.01$ \\
\hline & Type2 diabetes in HWE & 7 & $1.19(0.89-1.60)$ & $1.19(0.88-1.61)$ & 0 & 0.48 \\
\hline \multirow{10}{*}{$\begin{array}{l}\text { Co-dominance } \\
\text { model }\end{array}$} & All & 14 & $1.13(0.99-1.30)$ & $1.15(0.87-1.52)$ & 74 & $<0.01$ \\
\hline & Excluded $\mathrm{HWE}^{\mathrm{a}}$ & 11 & $0.93(0.79-1.08)$ & $0.93(0.77-1.11)$ & 22 & 0.23 \\
\hline & $\begin{array}{l}\text { Excluded } \\
\text { microalbumuria }{ }^{b}\end{array}$ & 8 & $0.95(0.79-1.13)$ & $0.94(0.74-1.19)$ & 40 & 0.12 \\
\hline & Excluded CRF/ESRD ${ }^{c}$ & 11 & $1.03(0.87-1.22)$ & $1.06(0.81-1.39)$ & 59 & 0.01 \\
\hline & Caucasian & 7 & $0.99(0.83-1.19)$ & $1.00(0.81-1.22)$ & 20 & 0.27 \\
\hline & East Asian & 5 & $1.07(0.82-1.39)$ & $1.09(0.61-2.00)$ & 78 & $<0.01$ \\
\hline & East Asian in HWE & 3 & $0.71(0.51-0.99)$ & $0.71(0.50-1.01)$ & 8 & 0.33 \\
\hline & Type1 diabetes & 4 & $1.05(0.81-1.37)$ & $1.06(0.79-1.42)$ & 15 & 0.32 \\
\hline & Type 2 diabetes & 10 & $1.16(0.99-1.37)$ & $1.17(0.80-1.72)$ & 80 & $<0.01$ \\
\hline & Type 2 diabetes in HWE & 7 & $0.87(0.72-1.05)$ & $0.86(0.68-1.07)$ & 25 & 0.24 \\
\hline
\end{tabular}




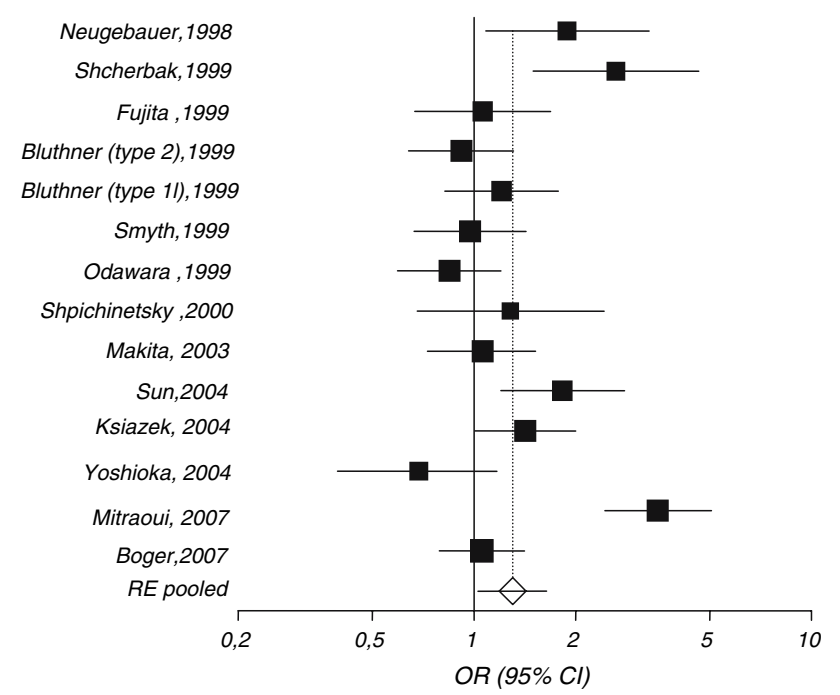

Fig. 1 Random effects (RE) odds ratio (OR) estimates with the corresponding $95 \%$ confidence interval (CI) for the allele contrast $\mathrm{T}$ vs $\mathrm{C}$ of MTHFR C677T gene polymorphism. The OR estimate of each study is marked with a solid black square. The size of the square represents the weight that the corresponding study exerts in the metaanalysis. The CIs of pooled estimates are displayed as a horizontal line through the diamond. The horizontal axis is plotted on a log scale

diabetes, the heterogeneity was again significant $\left(P_{\mathrm{Q}}<\right.$ $0.01, I^{2}=80 \%$ and $P_{\mathrm{Q}}<0.01, I^{2}=80 \%$, respectively), and the associations were not significant: $\mathrm{RE} \mathrm{OR}=1.29(0.90$ $1.86)$ and $\mathrm{RE} \mathrm{OR}=1.30(0.95-1.76)$, respectively.

The recessive model derived significant results overall [FE OR $\left.=1.32(1.10-1.58), P_{\mathrm{Q}}=0.27, I^{2}=17 \%\right]$, and in type 2 diabetes $\left[\mathrm{FE}\right.$ OR $=1.30(1.06-1.60), P_{\mathrm{Q}}=0.38$, $I^{2}=7 \%$; however, sensitivity analysis for HWE diminished the latter result. The sensitivity analysis for CRF/ ESRD did not alter the overall significance $[\mathrm{FE}$ OR $=1.32$ (1.05-1.67), $\left.P_{\mathrm{Q}}=0.58, I^{2}=0 \%\right]$. The dominant model produced a marginal significant association overall $[\mathrm{RE}$ $\left.\mathrm{OR}=1.41 \quad(1.01-1.97), \quad P_{\mathrm{Q}}<0.01, \quad I^{2}=81 \%\right] . \quad$ Then, overall, the additive model produced significant association $\left[\begin{array}{ll}\mathrm{RE} & \mathrm{OR}=1.65 \quad(1.13-2.42), \quad P_{\mathrm{Q}}<0.01, \quad I^{2}=66 \%\end{array}\right]$, whereas the co-dominant model did not $[\mathrm{RE} \mathrm{OR}=1.15$ $\left.(0.87-1.52), P_{\mathrm{Q}}<0.01, I^{2}=74 \%\right]$, as it was anticipated. A similar pattern of results was found for studies not involving cases with CFR/ESRD, Caucasians and type 2 diabetes; however, sensitivity analysis for HWE diminished the latter result.

\section{Potential bias}

None of the studies included in the meta-analysis stated that genotyping was performed blinded to clinical status. Overall, the cumulative and recursive meta-analyses for the allelic contrast showed that the RE OR declined from 1.88 in 1998 to 1.20 in 1999 (relative change $=64 \%$ ), and remained fairly constant in the period 1999-2004, and then increased to 1.30 in 2007 (relative change $=108 \%$ ) (Fig. 2). There is statistical difference between the OR of the first study versus the pooled OR of subsequent studies $(P=0.04)$. The pooled $\mathrm{OR}$ without the first study was RE $\mathrm{OR}=1.27 \quad(0.99-1.62)$. The Egger test and the BeggMazumdar test indicated that there is no differential magnitude of effect in large versus small studies $(P=0.57$ and $P=0.23$, respectively).

\section{Discussion}

Methylenetetrahydrofolate reductase (MTHFR) is involved in the transmethylation of homocysteine to methionine and a C677T polymorphism in the MTHFR gene yields a thermo-labile MTHFR variant with reduced enzymatic activity. This mutation is a genetic determinant of hyperhomocysteinemia in healthy subjects (Frosst et al. 1995; Kang et al. 1991) and also in patients with diabetes (Buysschaert et al. 2004). Hyperhomocysteinemia induces endothelial dysfunction (Constans et al. 1999) and it has been implicated as a risk factor not only for atherosclerosis and arterial or venous thrombosis (Frosst et al. 1995; McCully et al. 1969) but also for nephropathy in type 2 diabetes patients (Mtiraoui et al. 2007; Chico et al. 1998). Generally, hyperhomocysteinemia promotes the atherosclerotic and thrombotic process by modulating vascular cell proliferation and prothrombotic activities in the vascular wall (McCully et al. 1996; Constans et al. 1999). In addition, recent in vitro studies indicate that homocysteine and other thiol-containing reductive compounds (i.e. thiolactone) increase the expression of vascular endothelial growth factor (VEGF) in cell cultures via activation of $V E G F$ gene transcription (Maeda et al. 2003; Roybal et al. 2004). VEGF is a pro-angiogenic factor known to play a role in the pathogenesis of DN (Sung et al. 2006). For these reasons, it may be readily postulated that the C677T MTHFR gene polymorphism as a determinant of hyperhomocysteinemia might be involved in the development of DN.

This is the first meta-analysis to examine C677T polymorphisms of the MTHFR gene and their relationship to susceptibility for DN. The meta-analysis involved 15 studies, which provided 1,877 cases and 2,150 controls. The strength of the present analysis was based on the accumulation of published data giving greater information to detect significant differences. Non-English, non-indexed and non-published studies in the literature were not reviewed, thus suggesting bias (Egger et al. 1997; Zintzaras and Kaditis 2007). Studies demonstrating significant results are more likely to be published, especially in 


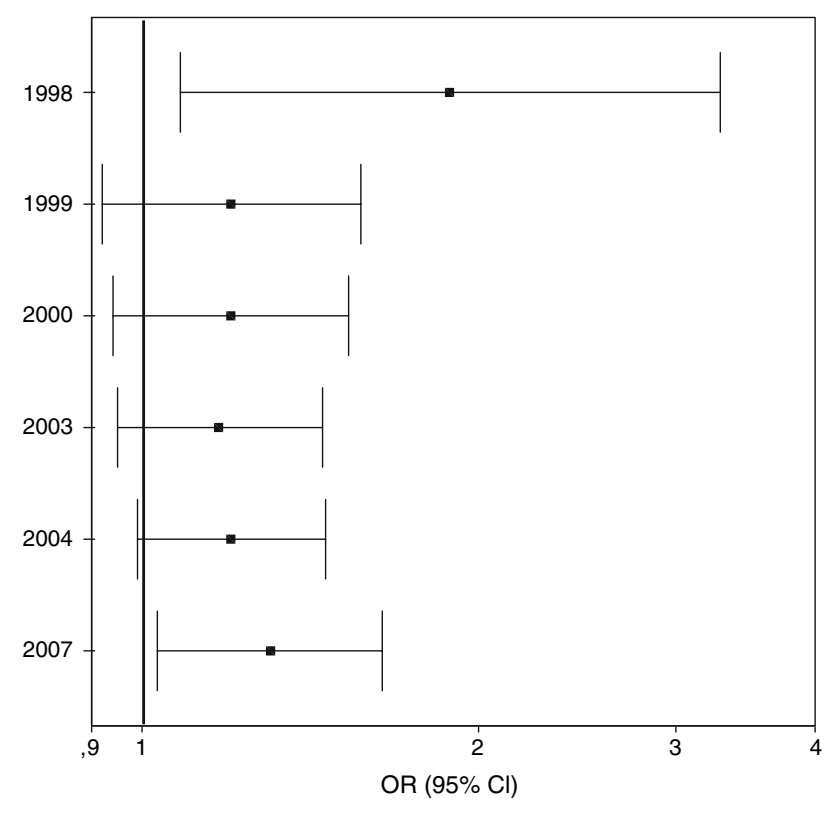

Fig. 2 Cumulative meta-analysis: the RE pooled OR with the corresponding $95 \% \mathrm{CI}$ at the end of each year-information step is shown

English language indexed journals, as opposed to studies presenting negative findings, which are more likely to be published in a local journal, often non-indexed. In the present study, the effect of allele frequency and the effects of the dominant, recessive, additive and co-dominance models were estimated. In addition, the consistency of genetic effects across populations from different ethnicities was investigated. Ethnicity was categorised into two main groups: (1) Caucasian descent, and (2) East Asian descent (Zintzaras et al. 2005, 2006c). However, the consistency of genetic effects across these traditionally defined ethnicities does not necessarily mean that ethnicity-specific genetic effects are exactly the same. Subgroup analysis by diabetes type, and sensitivity for studies not in HWE was carried out.

The overall data showed an excess of heterozygotes for cases, and an excess of homozygous CC alleles in controls. The main analysis (all studies) produced significant results for the allele contrast, the contrast of the extreme homozygotes, and the recessive and dominant models. The codominance model produced non-significant association. Overall, the meta-analysis results indicated that homozygocity in allele $\mathrm{T}$ was associated with a $65 \%$ increased risk of DN compared with homozygocity in allele $\mathrm{C}$, and it can be excluded with $95 \%$ certainty that heterozygotes would have less than $52 \%$ odds for developing DN and more than $15 \%$ for preventing DN. Caucasians and East Asians produced no significant associations, with similar estimated risks in all genetic contrasts. Type 2 diabetes showed significant results; however, sensitivity analysis diminished their significance, and thus, any interpretation must be cautious. In general, there is some indication of consistency of genetic effects between type 1 and 2 diabetes. The lack of association in subgroup analyses could be due to lack of power to detect existing significant associations and to other loci that are probably in linkage disequilibrium and that may affect (or mask) MTHFR susceptibility to DN (Imperatore et al. 1998). Cumulative meta-analysis showed a trend for stabilising the association as evidence accumulates, although the first published study showed an exaggerated association. There are no potential sources of bias, and there is no differential magnitude of effect in large versus small studies.

Sampling variability and stratification in case-control study design could be a possible confounding factor on the role of genetic markers. The meta-analysis included studies with a case group consisting of patients with persistent macro- or microalbuminuria, and thus the pooled estimated risk of DN may underestimate the true risk. However, the meta-analysis excluded case groups that consisted exclusively of patients with microalbuminuria. Although the presence of microalbuminuria may be an early finding in DN it is not invariably equivalent to it. A major limitation of using a meta-analytic approach for population-based observational studies is the confounding factors (e.g. age, sex, and lifestyle) that influence the estimates of associations. In this meta-analysis, only unadjusted pooled ORs could be calculated since data for each level of possible confounding factors were not provided. The cases and controls of each study were well defined and had similar inclusion criteria, although they unavoidably cover a wide spectrum of disease in terms of duration, demographics and other clinical manifestations. In addition, the risk effect may depend on the interaction with other risk factors, such as lifestyle (i.e. smoking, alcohol consumption, control of diabetes and body mass index), all of which directly modulate the development of DN (Passaro et al. 2003; Ma et al. 1997).

The present meta-analysis provided evidence that the TT genotype of the MTHFR C677T polymorphism contributes to susceptibility to DN. DN is a complex disease with a multifactorial etiology and therefore the contributing pathogenetic role of lifestyle factors and dietary intake should also be considered. The existence of gene-environment interactions may explain the discrepancy of results obtained in individual genetic association studies, and thus case-control studies that investigate gene-environment interactions (Clayton and McKeigue 2001) might help further elucidate the genetics of DN.

Acknowledgements We thank Nikos Sdoukopoulos for assistance in data extraction and Mauro Santos for comments and discussion on genetic contrasts. 


\section{References}

Begg CB, Mazumdar M (1994) Operating characteristics of a rank correlation test for publication bias. Biometrics 50:1088-1101

Bluthner M, Bruntgens A, Schmidt S, Strojek K, Grzeszczak W, Ritz E (1999) Association of methylenetetrahydrofolate reductase gene polymorphism and diabetic nephropathy in type 2 diabetes? Nephrol Dial Transplant 14:56-57

Boger CA, Stubanus M, Haak T, Götz AK, Christ J, Hoffmann U, Riegger GA, Krämer BK (2007) Effect of MTHFR C677T genotype on survival in type 2 diabetes patients with end-stage diabetic nephropathy. Nephrol Dial Transplant 22:154-162

Borch-Johnsen K, Norgaard K, Hommel E, Mathiesen ER, Jensen JS, Deckert T, Parving HH (1992) Is diabetic nephropathy an inherited complication? Kidney Int 41:719-722

Bostom AG, Selhub J, Jacques PF, Rosenberg IH (2001) Power shortage: clinical trials testing the "homocysteine hypothesis" against a background of folic acid-fortified cereal grain flour. Ann Intern Med 135:133-137

Boushey CJ, Beresford SA, Omenn GS, Motulsky AG (1995) A quantitative assessment of plasma homocysteine as a risk factor for vascular disease. Probable benefits of increasing folic acid intakes. JAMA 274:1049-1057

Buysschaert M, Gala JL, Bessomo A, Hermans MP (2004) C677T methylene-tetrahydrofolate reductase mutation in type 2 diabetic patients with and without hyperhomocysteinaemia. Diabetes Metab 30:349-354

Chico A, Perez A, Cordoba A, Arcelús R, Carreras G, de Leiva A, González-Sastre F, Blanco-Vaca F (1998) Plasma homocysteine is related to albumin excretion rate in patients with diabetes mellitus: a new link between diabetic nephropathy and cardiovascular disease? Diabetologia 41:684-693

Clayton D, McKeigue PM (2001) Epidemiological methods for studying genes and environmental factors in complex diseases. Lancet 358:1356-1360

Constans J, Blann AD, Resplandy F, Parrot F, Seigneur M, Renard M, Amiral J, Guérin V, Boisseau MR, Conri C (1999) Endothelial dysfunction during acute methionine load in hyperhomocysteinaemic patients. Atherosclerosis 147:411-413

DerSimonian R, Laird N (1986) Meta-analysis in clinical trials. Control Clin Trials 7:177-188

Egger M, Davey SG, Schneider M, Minder C (1997a) Bias in metaanalysis detected by a simple, graphical test. BMJ 315:629-634

Egger M, Zellweger-Zahner T, Schneider M, Junker C, Lengeler C, Antes G (1997b) Language bias in randomised controlled trials published in English and German. Lancet 350:326-329

Frosst P, Blom HJ, Milos R, Goyette P, Sheppard CA, Matthews RG, Boers GJ, den Heijer M, Kluijtmans LA, van den Heuvel LP (1995) A candidate genetic risk factor for vascular disease: a common mutation in methylenetetrahydrofolate reductase. Nat Genet 10:111-113

Fujita H, Narita T, Meguro H, Ishii T, Hanyu O, Suzuki K, Kamoi K, Ito S (1999) No association between MTHFR gene polymorphism and diabetic nephropathy in Japanese type II diabetic patients with proliferative diabetic retinopathy. J Diabetes Complicat 13:284-287

Goyette P, Sumner JS, Milos R, Duncan AM, Rosenblatt DS, Matthews RG, Rozen R (1994) Human methylenetetrahydrofolate reductase: isolation of cDNA, mapping and mutation identification. Nat Genet 7:195-200

Gross JL, de Azevedo MJ, Silveiro SP, Canani LH, Caramori ML, Zelmanovitz T (2005) Diabetic nephropathy: diagnosis, prevention, and treatment. Diabetes Care 28:164-176

Imperatore G, Hanson RL, Pettitt DJ, Kobes S, Bennett PH, Knowler WC (1998) Sib-pair linkage analysis for susceptibility genes for microvascular complications among Pima Indians with type 2 diabetes. Pima diabetes genes group. Diabetes 47:821-830

Ioannidis JP, Trikalinos TA, Zintzaras E (2006) Extreme betweenstudy homogeneity in meta-analyses could offer useful insights. J Clin Epidemiol 59:1023-1032

Kang SS, Wong PW, Bock HG, Horwitz A, Grix A (1991) Intermediate hyperhomocysteinemia resulting from compound heterozygosity of methylenetetrahydrofolate reductase mutations. Am J Hum Genet 48:546-551

Ksiazek P, Bednarek-Skublewska A, Buraczynska M (2004) The C677T methylenetetrahydrofolate reductase gene mutation and nephropathy in type 2 diabetes mellitus. Med Sci Monit 10:BR47-BR51

Lau J, Antman EM, Jimenez-Silva J, Kupelnick B, Mosteller F, Chalmers TC (1992) Cumulative meta-analysis of therapeutic trials for myocardial infarction. N Engl J Med 327:248-254

Ma J, Stampfer MJ, Giovannucci E, Artigas C, Hunter DJ, Fuchs C, Willett WC, Selhub J, Hennekens CH, Rozen R (1997) Methylenetetrahydrofolate reductase polymorphism, dietary interactions, and risk of colorectal cancer. Cancer Res 57:1098-1102

Maeda M, Yamamoto I, Fujio Y, Azuma J (2003) Homocysteine induces vascular endothelial growth factor expression in differentiated THP-1 macrophages. Biochim Biophys Acta 1623:4146

Makita Y, Moczulski DK, Bochenski J, Smiles AM, Warram JH, Krolewski AS (2003) Methylenetetrahydrofolate reductase gene polymorphism and susceptibility to diabetic nephropathy in type 1 diabetes. Am J Kidney Dis 41:1189-1194

McCully KS (1969) Vascular pathology of homocysteinemia: implications for the pathogenesis of arteriosclerosis. Am J Pathol $56: 111-128$

McCully KS (1996) Homocysteine and vascular disease. Nat Med 2:386-389

Moczulski D, Fojcik H, Zukowska-Szczechowska E, Szydlowska I, Grzeszczak W (2003) Effects of the C677T and A1298C polymorphisms of the MTHFR gene on the genetic predisposition for diabetic nephropathy. Nephrol Dial Transplant 18:15351540

Mtiraoui N, Ezzidi I, Chaieb M, Marmouche H, Aouni Z, Chaieb A, Mahjoub T, Vaxillaire M, Almawi WY (2007) MTHFR C677T and A1298C gene polymorphisms and hyperhomocysteinemia as risk factors of diabetic nephropathy in type 2 diabetes patients. Diabetes Res Clin Pract 75:99-106

Neugebauer S, Baba T, Watanabe T (1998) Methylenetetrahydrofolate reductase gene polymorphism as a risk factor for diabetic nephropathy in NIDDM patients. Lancet 352:454

Odawara M, Yamashita K (1999): A common mutation of the methylenetetrahydrofolate reductase gene as a risk factor for diabetic nephropathy. Diabetologia 42:631-632

Passaro A, Calzoni F, Volpato S, Nora ED, Pareschi PL, Zamboni PF, Fellin R, Solini A (2003) Effect of metabolic control on homocysteine levels in type 2 diabetic patients: a 3-year followup. J Intern Med 254:264-271

Quinn M, Angelico MC, Warram JH, Krolewski AS (1996) Familial factors determine the development of diabetic nephropathy in patients with IDDM. Diabetologia 39:940-945

Roybal CN, Yang S, Sun CW, Hurtado D, Vander Jagt DL, Townes TM, Abcouwer SF (2004) Homocysteine increases the expression of vascular endothelial growth factor by a mechanism involving endoplasmic reticulum stress and transcription factor ATF4. J Biol Chem 279:14844-14852

Shcherbak NS, Shutskaya ZV, Sheidina AM, Larionova VI, Schwartz EI (1999) Methylenetetrahydrofolate reductase gene polymorphism as a risk factor for diabetic nephropathy in IDDM patients. Mol Genet Metab 68:375-378 
Shpichinetsky V, Raz I, Friedlander Y, Goldschmidt N, Wexler ID, Ben-Yehuda A, Friedman G (2000) The association between two common mutations C677T and A1298C in human methylenetetrahydrofolate reductase gene and the risk for diabetic nephropathy in type II diabetic patients. J Nutr 130:2493-2497

Smyth JS, Savage DA, Maxwell AP (1999) MTHFR gene polymorphism and diabetic nephropathy in type 1 diabetes. Lancet 353:1156-1157

Strojek K, Grzeszczak W, Morawin E, Adamski M, Lacka B, Rudzki H, Schmidt S, Keller C, Ritz E (1997) Nephropathy of type II diabetes: evidence for hereditary factors? Kidney Int 51:16021607

Sun J, Xu Y, Zhu Y, Lu H (2004) Genetic polymorphism of methylenetetrahydrofolate reductase as a risk factor for diabetic nephropathy in Chinese type 2 diabetic patients. Diabetes Res Clin Pract 64:185-190

Sung SH, Ziyadeh FN, Wang A, Pyagay PE, Kanwar YS, Chen S (2006) Blockade of vascular endothelial growth factor signaling ameliorates diabetic albuminuria in mice. J Am Soc Nephrol 17:3093-3104

Weir BS (1996) Genetic data analysis II: methods for discrete population genetic data. Sinauer, Sunderland

Whitehead A (2002) Meta-analysis of controlled clinical trials. Wiley, Chichester

Yoshioka K, Yoshida T, Umekawa T, Kogure A, Takakura Y, Toda H, Yoshikawa T (2004) Methylenetetrahydrofolate reductase gene polymorphism is not related to diabetic nephropathy in Japanese Type 2 diabetic patients. Diabet Med 21:1051-1052

Zintzaras E (2006a) Association of methylenetetrahydrofolate reductase (MTHFR) polymorphisms with genetic susceptibility to gastric cancer: a meta-analysis. J Hum Genet 51:618-624

Zintzaras E (2006b) Methylenetetrahydrofolate reductase gene and susceptibility to breast cancer: a meta-analysis. Clin Genet 69:327-336

Zintzaras E (2006c) C677T and A1298C methylenetetrahydrofolate reductase gene polymorphisms in schizophrenia, bipolar disorder and depression: a meta-analysis of genetic association studies. Psychiatr Genet 16:105-115
Zintzaras E (2007) Brain-derived neurotrophic factor gene polymorphisms and schizophrenia: a meta-analysis. Psychiatr Genet 17:69-75

Zintzaras E, Hadjigeorgiou GM (2004) Association of paraoxonase 1 gene polymorphisms with risk of Parkinson's disease: a metaanalysis. J Hum Genet 49:474-481

Zintzaras E, Hadjigeorgiou GM (2005) The role of G196A polymorphism in the brain-derived neurotrophic factor gene in the cause of Parkinson's disease: a meta-analysis. J Hum Genet 50:560-566

Zintzaras E, Ioannidis JP (2005a) Heterogeneity testing in metaanalysis of genome searches. Genet Epidemiol 28:123-137

Zintzaras E, Ioannidis JP (2005b) HEGESMA: genome search metaanalysis and heterogeneity testing. Bioinformatics 21:3672-3673

Zintzaras E, Kaditis AG (2007) Sleep-disordered breathing and blood pressure in children: a meta-analysis. Arch Pediatr Adolesc Med 161:172-178

Zintzaras E, Stefanidis I (2005) Association between the GLUT1 gene polymorphism and the risk of diabetic nephropathy: a metaanalysis. J Hum Genet 50:84-91

Zintzaras E, Chatzoulis DZ, Karabatsas CH, Stefanidis I (2005) The relationship between $\mathrm{C} 677 \mathrm{~T}$ methylenetetrahydrofolate reductase gene polymorphism and retinopathy in type 2 diabetes: a meta-analysis. J Hum Genet 50:267-275

Zintzaras E, Kitsios G, Stefanidis I (2006a) Endothelial NO synthase gene polymorphisms and hypertension: a meta-analysis. Hypertension 48:700-710

Zintzaras E, Rodopoulou P, Koukoulis GN (2006b) BsmI, TaqI, ApaI and FokI polymorphisms in the vitamin D receptor (VDR) gene and the risk of osteoporosis: a meta-analysis. Dis Markers 22:317-326

Zintzaras E, Koufakis T, Ziakas PD, Rodopoulou P, Giannouli S, Voulgarelis M (2006c) A meta-analysis of genotypes and haplotypes of methylenetetrahydrofolate reductase gene polymorphisms in acute lymphoblastic leukemia. Eur J Epidemiol 21:501-510

Zintzaras E, Stefanidis I, Santos M, Vidal F (2006d) Do alcoholmetabolizing enzyme gene polymorphisms increase the risk of alcoholism and alcoholic liver disease? Hepatology 43:352-361 